\title{
Review of Breast Cancer Cases Admitted In Hospital Sultanah Bahiyah, Alor Setar, Malaysia
}

\author{
${ }^{1,}$ Dr. Krishna Kumar Mallick, ${ }^{2,}$ Mr. Lim Huay Cheen \\ ${ }^{1}$ M.B.B.S.(Gold Medalist), MS(General Surgery), F.C.G.P.(India), F.S.A.S.M.S.(Delhi), M.R.S.H.(London). \\ 'Associate Professor, Surgery Unit, Faculty of Medicine, AIMST University, Malaysia. \\ 2.Hospital Sultanah Bahiyah, Alor Setar, Malaysia. \\ Data compiled and references collected by:--- \\ 1. Ooi Shu Huey 2.Woon Yee Ling 3.Yee Thean Sim 4. Loh Sue Anne \\ All outgoing final year MBBS students of AIMST University.
}

\begin{abstract}
It has been observed globally that breast cancer cases usually report to the doctors at a late stage. The impact of 'late reporting' has been of great consequences on the post-treatment morbidity and mortality of the patients. In the present project, it has been tried to assess breast cancer cases admitted and treated at Hospital Sultanah Bahiyah,Alor Setar, which is the main referral hospital of Kedah State of Malaysia. For this project we analyzed about 332 breast cancer cases admitted in this hospitalbetween 2008 to 2012.
\end{abstract}

Abbreviation: HSB-Hospital Sultanah Bahiyah, AlorSetar .BC---Breast Cancer. CT---Computerized Tomography. F---Female. M---Male. NCR - National Cancer Registry.

KEY WORDS : Breast cancer, carcinoma-in-situ, intra ductal carcinoma, breast conservative surgery.

\section{INTRODUCTION}

Breast carcinoma (BC) is commonest life-threatening carcinomas in females. About 1.4 million new cases are diagnosed every year. In 2008, BC accounted for about $11 \%$ of all cancers diagnosed through out the world. (1) In Malaysia too BC is commonest among all the cancers found in both the sexes. As per National Cancer Registry (NCR) statistics 3242 female BC cases were diagnosed in 2007, which was $18.1 \%$ of all the cancer cases diagnosed that year and $32.1 \%$ of all female cancer cases. As per the statistics BC is more common in the age group of 40 to 55 in Malaysia.(2) It has been established that early diagnosis of the condition leads to better survival rate.(3) Contrary to that reporting at an advanced stage accounts for poor prognosis and less overall survival.(4) In a follow up study of 20 years, it has been found that patient delay beyond 3 months reduce the survival by $10 \%$.(5) In Malaysia accessibility to health care may not be a key factor, but still there is a delay in reporting the cases. Though population based screening mammogram is not practiced widely in the country (6), but whether it is the sole factor for delay in reporting to the doctor! $\mathrm{BC}$ is not rare in males also. In Malaysia, NCR recorded 56 new male BC cases in 2002 and 24 cases in 2003. So, men shouldn't die of BC, only because of the fact that they presume themselves to be immune to breast cancer. As males have worse prognosis, detection in early stage of $\mathrm{BC}$ would insure better chances of successful treatment.(7)

\section{AIM AND OBJECTIVE}

The aim of present study is to evaluate the staging of $\mathrm{BC}$ when the patient first comes to the doctor. For this, clinical and pathological TNM staging have been taken into account. Many early BC patients are asymptomatic, especially if diagnosed during a breast-screening program. Rarely pain may be an early feature, which draws the attention of the patient and she comes for medical advice. Occasionally, swelling may be an incidental finding during self palpation of the breast by the patient or by the physician. The main objective of this study is to promote early detection of $\mathrm{BC}$ so that prompt treatment can be done to reduce the morbidity and mortality.

\section{INCLUSION CRITERIA}

All the BC patients admitted in HSB, Malaysia from the year 2008 to 2012 were included in the present study. Data collected includes the hospital no., age, gender and race. 


\section{Results and Discussion}

All the results are being presented in tabular form----

\begin{tabular}{|l|l|l|l|}
\hline S.No. & Race & No.of cases & Percentage \\
\hline 1. & Chinese & 52 & 15.7 \\
\hline 2. & Indian & 15 & 4.5 \\
\hline 3. & Malay & 257 & 77.4 \\
\hline 4. & Others & 8 & 2.4 \\
\hline 5. & Total & 332 & 100 \\
\hline
\end{tabular}

Depending upon this chart we cannot infer that Malay are more susceptible to BC, because. (8)-

Population of Malay here is much more than Chinese, Indians or others.

Most of the Chinese and Indian patients prefer private hospitals than the Govt. hospitals.

\begin{tabular}{|l|l|c|l|}
\hline S.No. & Age & No. of cases & percentage \\
\hline 1. & $21-30$ & 7 & 2.1 \\
\hline 2. & $31-40$ & 34 & 10.2 \\
\hline 3. & $41-50$ & 107 & 32.2 \\
\hline 4. & $51-60$ & 104 & 31.3 \\
\hline 5. & $61-70$ & 57 & 17.2 \\
\hline 6. & $71-80$ & 19 & 5.7 \\
\hline 7. & $81-90$ & 4 & 1.2 \\
\hline 8. & Total & 332 & 100 \\
\hline
\end{tabular}

By mere observation of the above chart, it becomes obvious that most cases of $\mathrm{BC}$ belonged to the age group of 41 years to 60 years. About $63.5 \%$ of cases were found in this age group only. Youngest patient of BC, who was admitted between 2008 to 2012 was 26 years old. Again this observation may not be quite correct, as elderly women in rural areas generally do not come to the doctor and go for home-remedies only and reporting to NCR is done by doctors and not by the general public. Hospital documents also showed that 3 of the $332 \mathrm{BC}$ cases were $\mathrm{M}$ and rest $\mathrm{F}$. So, only about $0.9 \%$ cases of $\mathrm{BC}$ belonged to males.

\begin{tabular}{|l|l|l|}
\hline Side & No. of cases & Percentage \\
\hline Left & 168 & 50.6 \\
\hline Right & 140 & 42.2 \\
\hline Both & 24 & 7.2 \\
\hline Total & 332 & 100 \\
\hline
\end{tabular}

This chart shows that $50.6 \%$ cases of BC were left sided, while $42.2 \%$ were on right side. About $7.2 \%$ cases presented with bilateral carcinoma. Till now, no studies have established the preference of side in BC.

\begin{tabular}{|l|c|l|}
\hline Type of cancer & No. of cases & Percentage \\
\hline Ductal carcinoma & 309 & 93.1 \\
\hline Lobular carcinoma & 17 & 5.1 \\
\hline Other types(Papillary carcinoma, Paget's disease) & 6 & 1.8 \\
\hline & 332 & 100 \\
\hline
\end{tabular}

By above chart it is quite clear that $93.1 \%$ cases belonged to ductal carcinoma category, while only $6.9 \%$ cases were of other types. The exact cause of this incidence is not clear.

\begin{tabular}{|l|l|l|}
\hline Size of tumor at the time of reporting & No. of cases admitted & Percentage \\
\hline T0 & 6 & 1.8 \\
\hline T1 & 30 & 9 \\
\hline T2 & 96 & 28.9 \\
\hline T3 & 52 & 15.7 \\
\hline T4 & 104 & 31.3 \\
\hline Data missing/Incomplete & 44 & 13.3 \\
\hline Total & 332 & 100 \\
\hline
\end{tabular}

Here, $\quad T 0=$ No evidence of tumor; T1= Size of tumor $<20 \mathrm{~mm}$. in greatest dimension. 
$\mathrm{T} 2=$ Size $>20 \mathrm{~mm} .<50 \mathrm{~mm} . ; \mathrm{T} 3=$ Size $>50 \mathrm{~mm} . \mathrm{T} 4=$ Any size with direct invasion of the chest wall $/$ skin (ulceration or skin nodules). As per the above chart, majority of BC (31.3\%) presented to the hospital at T4 stage followed by T2 patients (28.9\%), T3 patients (15.7\%) and T0 patients (1.8\%).If we ignore 24 cases, data of which were not found/incomplete, one thing is quite obvious that $47 \%$ cases of $\mathrm{BC}$ presented to the doctor at a much advanced stage of T3 and T4, when either the tumor becomes more than $5 \mathrm{~cm}$. in diameter or skin and chest wall had been invaded by the malignant tumor. So, almost about half of the patients selected for this project came to the clinic at an advanced stage of BC. This may be due to lack of awareness about BC in Kedah women. It may be because majority of patients admitted in govt. hospitals come from rural areas.

\begin{tabular}{|l|l|l|}
\hline Clinically palpable lymph node (stage) & No. of patients & Percentage \\
\hline N0 & 154 & 46.4 \\
\hline N1 & 71 & 21.4 \\
\hline N2 & 27 & 8.1 \\
\hline N3 & 17 & 5.1 \\
\hline Data N.A./ missing & 63 & 19 \\
\hline Total & 332 & 100 \\
\hline
\end{tabular}

This chart shows us that majority (46.4\%) of cases admitted had no palpable lymph node (N0). It has not much significance as it is examiner dependent. Sometimes deep-seated enlarged lymph nodes may not be palpable.

\section{CONCLUSION}

By studying all above data, we come to the conclusion that majority of BC cases admitted in HSB belonged to advanced stage (stage 3 and 4). If we talk about pathological staging, almost half of the patients (49\%) belonged to stage 3 or 4 . In clinical staging, we are finding that 104 patients (31.3\%) admitted had T4 tumor, followed by 96 (28.9\%) with T2. In this way we see that majority of patients of BC came to the hospital when their tumor became big or skin and chest wall invaded. Our data regarding racial distribution showed that about $77.4 \%$ of Malay, $15.4 \%$ Chinese, $4.5 \%$ Indian and $2.4 \%$ of other races were admitted in HSB with BC during 2008-2012. As far as sex of the patients is concerned, $99.1 \%$ of BC were females and only $0.9 \%$ were male; while age curve was bell shaped, with most of the patients (63.5\%) belonging to 41 to 60 age group.(8). $50.6 \%$ of cases had right sided BC, while $42.2 \%$ had left sided and only $7.2 \%$ had bilateral BC. Majority (93.1) $\mathrm{BC}$ were ductal carcinoma, while only $5.1 \%$ had lobular carcinoma and $1.8 \%$ had other types of carcinoma.

\section{SUMMARY}

In summary, it was observed that majority of the patients admitted in HSB during 2008 to 2012 had late stage (stage 3 and 4 ) of BC. About $49 \%$ of BC patients had pathological stage III and IV.

So, it is very important for the concerned people to be more particular to aware the women folk, especially in the rural areas, regarding early features of $\mathrm{BC}$ and prognosis of cancer if they report to the doctor at a late stage.

\section{REFERENCES}

[1] Ferlay J, Shin HR, Bray F, Forman D, Mathers C, Parkin DM. GLOBOCAN 2008, vol.2, Cancer Incidence and Mortality worldwide: IARC Cancer Base no. 10 (Internet). Lyon, France: International Agency for Research on cancer, 2010.

[2] http://globoscan.iarc.fr.

[3] O Zainal Ariffin, I.T. Nor Saleha, NCR Report,2007, Ministry of Health, Malaysia, 2011.

[4] About Breast Cancer, Epromed Services, SdnBhd for the college of Radiology, Academy of Medicine of Malaysia.

[5] Cheng Har Yip, Nur Aishah Mohd. Taib, Ibraham Mohamed, Epidemiology of Breast Cancer in Malaysia, Asian Pacific Journal of Cancer prevention, Vol. 7, 2006. <http://www.apocpcontrol.com/paper_

file/issue_abs/volume7_No3/Cheng\%20Har\%20Yip.pdf>

[6] Breast Cancer, Medscape, WebMD, LLC

[7] Richards MA, Smith P, Ramirez AJ, Fentiman IS, Rubens RD(1999), The Influence on survival of delay in the presentation and treatment of symptomatic breast cancer, Br J Cancer, pp 79, 858-64.

[8] Taib NA, Akmal NA, Mohamed I, Yip CH(2011), Improvement in survival of delay breast cancer patients. Trends in survival over two time periods in a single institution in an Asia Pacific Country, Malaysia, Asian Pac J of Cancer Prevention, pp 12345 9. 